\title{
Liposomes as New Approaches in the Treatment of Bacterial and Parasitic Infections in Domestic Animals
}

Sandrelli Meridiana de Fátima Ramos dos Santos Medeiros ${ }^{1}$, Sérgio Dias da Costa Junior ${ }^{1,2}$, Luís André de Almeida Campos ${ }^{1}$, Sarah Brandão Palácio ${ }^{1}$ and Isabella Macário Ferro Cavalcanti ${ }^{1,3 *}$

${ }^{1}$ Laboratório de Imunopatologia Keizo Asami, Universidade Federal de Pernambuco (UFPE), Brazil

${ }^{2}$ Departamento de Medicina Tropical, Universidade Federal de Pernambuco (UFPE), Brazil

${ }^{3}$ Laboratório de Microbiologia e Imunologia, Universidade Federal de Pernambuco (UFPE), Centro Acadêmico de Vitória (CAV), Brazil

Submission: October 27, 2018; Published: November 19, 2018

"Corresponding author: Isabella Macário Ferro Cavalcanti, Universidade Federal de Pernambuco (UFPE), Brazil

Laboratório de Imunopatologia Keizo-Asami (LIKA), Av. Prof. Moraes Rego, 1235, Cidade Universitária, 50670-901, Recife, PE, Brazil

\begin{abstract}
Parasitic infections and bacterial infections, especially those caused by bacteria resistant to antimicrobial agents, are known to provide high morbidity and mortality rates in domestic animals worldwide. The drugs used in the treatment of these infections may present toxicity and low bioavailability, delaying the recovery process of these animals. In this context, nanotechnology appears as a new approach for the development of new effective pharmaceutical dosage forms of these drugs, aiming a better biodistribution and decrease of adverse events. Nanocarriers, such as liposomes, have great potential for the delivery of bioactive substances due to their biocompatibility, biodegradability and low toxicity. Liposomes can be used in a variety of fields, including veterinary medicine, and have made great strides in recent decades. Thus, the present study aims to highlight the main and most recent scientific discoveries about the promising potential of liposomes as nanocarriers of drugs in the treatment of parasitic and bacterial infections in domestic animals.
\end{abstract}

Keywords: Domestic animals; Parasitic infections; Bacterial infections; Nanotechnology; Liposomes

Abbreviations: MRSA: Methicillin Resistant Staphylococcus Aureus; MRSP: Methicillin Resistant Streptococcus Pyogenes; MDR: Multidrug Resistant Acinetobacter Baumannii; ESBL: Extended Spectrum $\beta$-lactamase-producing Enterobacteriaceae

\section{Introduction}

Parasitic infectious diseases, such as giardiasis, toxoplasmosis and leishmaniasis, bacterial diseases, such as leptospirosis, campylobacteriosis, salmonellosis, and infections caused by microorganisms with resistance profile are among the leading cause of morbidity and mortality in domestic and wild animals. The high prevalence of these infections in domestic animals can represent a serious threat to human health due to the zoonotic potential of many of these microorganisms, as well as the spread of these infections among animals of the same species, which may lead to the sacrifice of these animals $[1,2]$. In addition, in recent decades, many of the bacterial infections in companion animals are caused by resistant microorganisms. Bacterial resistance is an unavoidable consequence of natural selection, but some factors can accelerate its emergence, among them the inappropriate use of antimicrobial agents in human and animal health $[1,3]$.

Although most drugs exhibit effective antibacterial and/or antiparasitic activities against these infections, these compounds demonstrate restrictions on their use in clinical practice, such as its side effects and low bioavailability. The resistance to the antimicrobial agents that some microorganisms have been presenting due to the continuous use of these drugs is also troublesome. Thus, nanotechnology arises as a powerful tool to overcome the pharmacological difficulties of these molecules, making them viable as therapeutic options, aiming for greater treatment efficacy and lower toxicity $[4,5]$.

Among nanobiotechnology products, nanocarriers for drug-controlled release, such as liposomes, appear as potential applications. Liposomes can be defined as vesicles having one or more phospholipid bilayers around an aqueous core. These nanocarriers are widely used as drug delivery systems because of their efficiency, biocompatibility, non-immunogenicity, and their ability to encapsulate hydrophilic and hydrophobic molecules $[6,7]$. Liposomes maintain the concentration of the drug within the therapeutic range, decrease its side effects and increase the bioavailability of the encapsulated drug, thus increasing patient compliance with treatment [8]. Liposome formulations are already used in the clinical routine of infections in humans and in domestic and wild animals [4,9]. In this context, are been realized new research and dissemination of studies related to the application of nanotechnologies approaches, such as liposomes, in the treatment of infections in domestic animals, aiming to obtain new therapeutic options for systemic infections in animals and the diffusion of the multidisciplinary knowledge which involves veterinary medicine and pharmaceutical nanotechnology.

Bacterial and parasitic infections in domestic animals Zoonoses, which are diseases transmitted to humans through 
animals, are a global concern since they affect the entire world population, particularly affecting elder people, pregnant or immunocompromised, groups more susceptible to infections [10]. Commonly, the zoonoses are transmitted by domesticated pets, as they may be infected and/or colonized with a wide variety of pathogenic bacteria and parasites [11].

Children and the elderly are generally more exposed to pathogenic organisms from domestic animals, since they sometimes present lacks effective hygiene standards and greater physical contact with these animals and the domestic environment [10]. Contamination occurs through different routes, such as bites, scratches, inhalation, and food and water intake, besides contact with urine, feces or environments contaminated by microorganisms $[10,11]$.

Domestic animals can be affected by bacterial and parasitic infections. Among the bacterial infections, salmonellosis, campylobacteriosis, leptospirosis and infections caused by bacterial with resistance profile stand out. Salmonellosis is an infection caused by Salmonella spp. which can survive for weeks or months in the environment, especially in hot and humid places. This bacterium has reptiles as natural reservoir, but colonizes dogs and cats, especially those lost or sheltered, as well as those who eat raw food [12].

Campylobacteriosis is a foodborne infection and can be transmitted by pets. Its etiologic agent is bacteria of the genus Campylobacter and is associated with human gastroenteritis. Dogs and cats are carriers of these microorganisms, especially in the newborn puppies [13]. Leptospirosis is considered a reemerging disease caused by species of the genus Leptospira that can survive for long periods of time in hot and humid environments. This disease can affect dogs and cats, particularly those that are abandoned, and can be considered a serious and highly contagious disease [10].

Infections caused by bacterial with resistance profile affecting dogs and cats are being an emerging human and animal health problem. These infections have as their etiological agents' methicillin-resistant Staphylococcus aureus (MRSA), methicillin-resistant Streptococcus pyogenes (MRSP), extended spectrum $\beta$-lactamase-producing Enterobacteriaceae (ESBL) and multidrug-resistant Acinetobacter baumannii (MDR) [14]. Studies report that the risk of domestic animals acquiring resistant strains is particularly high. Contact with pets is a highrisk factor for human infections by resistant bacteria, since strains that correspond to clones disseminated by dogs and cats have been found in the human population, suggesting home transmission of resistant strains between pets and their owners [15].

Among the parasitic diseases that affect the animals are giardiasis, leishmaniasis and toxoplasmosis. Giardiasis is caused by the protozoan Giardia duodenalis and this infection has been widely reported in humans and domestic animals. Domestic dogs and cats are vulnerable to gastrointestinal infections caused by this parasite [16]. Cutaneous leishmaniasis is caused by the parasite of the genus Leishmania and is transmitted to humans and other mammals by the bite of a phlebotomine infected sand flies. Dogs are hosts and reservoirs in different parts of the world and are responsible for maintaining transmission of leishmaniasis in different locations $[17,18]$. Toxoplasmosis is a parasitic disease caused by Toxoplasma gondii and presents a high incidence in humans, reaching $50-60 \%$ of the world population. Cats and dogs infected with $\mathrm{T}$. gondii may present risks to human health, especially in areas where these animals live close to humans $[16,19]$.

Intestinal parasitic infections are the most common diseases among humans and domestic animals, such as dogs, cats and pigs, being these hosts reservoirs of the parasites Ancylostoma ceylanicum, Ascaris spp., Trichuris spp. (pigs), Echinostoma spp. and Cryptosporidium spp. Dogs and cats are associated with more than 60 zoonotic parasites and have potential to transmit due to association with family members, being one of the serious public health hazards worldwide [20].

\section{Nanotechnology and Nanomedicine}

Nanotechnology is a specific field of science dedicated to the construction and material handling of functional structures at the nanometer scale, often 1 to $100 \mathrm{~nm}$, but usually extends to include materials smaller than $1 \mu \mathrm{m}$ [21]. Nanotechnology applications targeting human and veterinary medicine, known as nanomedicine, have progressively increased in recent years, making nanotechnology an extremely promising area in veterinary medicine. The materials developed through nanomedicine have great potential to overcome serious hazards related to animal health, in addition to the preventive action, diagnoses and treatments for the several diseases that can attack them [22]. Among the nanocarriers, we highlight the liposomes, nanocarriers that were first described in 1961 and are defined as vesicles composed of one or more bilayers of phospholipids and an aqueous nucleus within these bilayers. The presence of an aqueous core and a lipid bilayer make liposomes be considered highly versatile delivery systems capable of incorporating hydrophilic and lipophilic molecules [8].

Liposomes can be conjugated to antibodies or ligands designed to optimize their suitability for the intended route and action site. They are developed to be generally administered intravenously and intramuscularly, but are vulnerable to degradation in the gastrointestinal tract, so they are rarely used for oral route. Liposomes are commonly studied to improve the targeting of drugs and vaccines [8]. In this sense, nanotechnology is a set of technologies that are used individually or in combination to produce products and applications in various fields, including in veterinary medicine [22].

\section{Liposomes for the Treatment of Bacterial and Parasitic Infections}

Liposomes may act directly or indirectly in the microorganism, or by activating the immune system. The first studies of the 
efficacy of liposomal formulations in dogs occurred in the early 1980s [23,24]. Since then, several studies looking at ways to incorporate drugs into liposomes and to develop new treatments for bacterial and parasitic infections for these animals. One of the first studies using liposomes to treat Toxoplasma gondii was performed by Mellors [25], which showed that recombinant IFN- $\gamma($ rIFN- $\gamma$ ) encapsulated into liposomes was ten times more potent in the activation of macrophages to produce $\mathrm{H} 2 \mathrm{O} 2$ and improve the anti-Toxoplasma activity of rIFN- $\gamma$, as well as prolong its effects. In another study, El-Zawawy [26] purpose the treatment of tachyzoites T. gondii-infected mice with triclosan (TS) $(150 \mathrm{mg} / \mathrm{kg} /$ day) and TS encapsulated in liposomes $(100 \mathrm{mg} / \mathrm{kg} /$ day). The animals of the infected and untreated group showed a decrease in food intake and lethargic behavior. The number of tachyzoites decreased in the peritoneal fluid and in the liver smear of all treated groups, nevertheless a significant reduction in parasite load was observed in the group treated with TS encapsulated in liposomes compared to the group treated with TS.

Uric acid, a natural compound found in some species of lichens of the genus Usnea, has a variety of biological effects, including activity against protozoa $[27,28]$. Due to their toxicity and low water solubility, the use of liposomes may enhance the transport of this drug to the target cells. Analysis of the therapeutic effects of usnic acid and liposomes containing usnic acid $(\sim 130 \mathrm{~nm})$ was performed by Si [29] in Swiss mice infected intraperitoneally with tachyzoites of the Toxoplasma gondii $\mathrm{RH}$ strain. The authors found higher survival rates in mice treated with usnic acid encapsulated into liposomes when compared with mice treated only with usnic acid and concluded that liposomes containing usnic acid present a low toxicity, inhibitory effect on toxoplasma tachyzoite viability and promote a destruction of organelle membranes related to virulence.

Enrofloxacin, a second generation of fluoroquinolones, is used as a veterinary medicinal product for the treatment of salmonellosis due to its antibacterial properties [30]. Notwithstanding, this molecule achieves lower intracellular concentrations, which implies in failure of treatment, drug resistance, high incidence of relapse and toxicity to some organs. Therefore, the elimination of intracellular Salmonella, mainly in macrophages, requires new therapeutic strategies. Hence, nanocarriers can accumulate into macrophages and other cells, which makes them potentially useful for the treatment of intracellular infections, including Salmonellosis. Liposomes and polymeric nanoparticles have been reported as efficient nanocarriers, increasing the intracellular accumulation of fluoroquinolones at the site of infection with reduced toxicity and side effects [31].

Studies demonstrate the efficacy of liposomal enrofloxacin in delivery the drug to the monocytes of sheepdogs, resulting in a more effective treatment against intracellular infections compared to the drug in its free form [32,33]. Enrofloxacin encapsulated in multilamellar liposomes also increase the drug concentration in blood cells of dogs and was a more effective treatment for intracellular S. aureus infections [34]. In a similar way, another study showed that the use of liposomes resulted in an increased enrofloxacin activity against $S$. aureus in sheep dog neutrophils [35].

Pentavalent antimonials are first-line drugs for the treatment of leishmaniasis. The recommended treatment with these drugs has demonstrated good clinical efficacy, however, its use is limited by the need of daily parenteral administration, besides the serious side effects and treatment failures, since the treatment does not eliminate the infection [5]. In this context, several nanocarriers, such as liposomes, are designed for the targeting of antimonial drugs to the sites of visceral leishmaniasis infection, as well as for oral and topical antimony administration in visceral and cutaneous leishmaniasis [5].

A research conducted by Ribeiro [36] evaluated the antiparasitic activity of liposomes containing meglumine antimoniate (AML) against Leishmania spp. Dogs were infected with the parasite and treated parenterally with AML, liposomes without the drug and saline solution. A significant reduction in dog infection was found in the AML treated group when compared to the other groups. Another important study conducted in Brazil by da Silva [37] included 52 infected dogs distributed in six treatment groups: liposomes containing meglumine antimoniate, allopurinol, liposomal formulation of antimoniate plus allopurinol, liposomes containing allopurinol, liposomes without drug and saline solution. The authors observed that AML promoted both long-term suppression of the parasite and the reduction of infectious load in treated dogs. Despite these results, 5 months after treatment, the parasites were still found in the bone marrow of the animals. In this way, the researchers decided to compare the effectiveness of the treatment with AML with the treatment using AML associated with allopurinol. This therapeutic combination has been shown to promote clinical improvement and a significant decrease in the parasite load in the bone marrow and spleen of dogs, in addition to minimize the toxicity of these drugs by their encapsulation in liposomes.

\section{Conclusion}

In view of the foregoing, the use of liposomes to control the delivery of antibacterial and antiparasitic drugs and overcome their serious pharmaceutical limitations, such as toxicity and bioavailability, can improve significantly the in vivo efficacy and safety of these drugs. Moreover, this promising therapeutic approach can also be designing to target organs that present higher bacterial or parasite loads, improving the specificity of drugs for the treatment of bacterial and parasitic infections for veterinary applications.

\section{References}

1. Ishii JB, Freitas JC, Arias MVB (2011) Resistência de bactérias isoladas de cães e gatos no Hospital Veterinário da Universidade Estadual de Londrina. Pesq Vet Bras 31(6): 533-537. 
2. Travi BL, Silva AC, Dantas-Torres F, Miro G (2018) Canine visceral leishmaniasis: Diagnosis and management of the reservoir living among us. PLOS Negl Trop Dis 12(1): 1-13.

3. Costa-Junior SD, Campos LAA, Palácio SB, Cavalcanti IMF (2018) Silver Nanoparticles as a Promising Therapeutic Strategy for Infections Caused by Resistant Bacteria in Cattle and Birds. Appro Poult Dairy \& Vet Sci 4(3): 1-5.

4. Silva SM, Amorim IFG, Ribeiro RR, Azevedo EG, Demicheli C, et al. (2012) Efficacy of Combined Therapy with Liposome-Encapsulated Meglumine Antimoniate and Allopurinol in Treatment of Canine Visceral Leishmaniasis. Antimicrob Agents Chemother 56(6): 28582867.

5. Frézard F, Demicheli C, Silva SM, Azevedo EG, Ribeiro RR (2017) Nanostructures for Improved Antimonial Therapy of Leishmaniasis. Nano-and Microsc Drug Deliv Sys 1(22): 419-437.

6. Deshpande PP, Biswas S, Torchilin VP (2013) Current trends in the use of liposomes for tumor targeting. Nanomed 8(9): 1509-1528.

7. Sercombe L, Veerati T, Moheimani F, Wu SY, Sood AK, et al. (2015) Advances and challenges of liposome assisted drug delivery. Front Pharma 6(286): 1-13

8. Pattni BS, Chupin VV, Torchilin VP (2015) New developments in liposomal drug delivery. Chem Ver 115(19): 10938-10966.

9. Schettini DA, Ribeiro RR, Demicheli C, Rocha OG, Melo MN, et al. (2006) Improved targeting of antimony to the bone marrow of dogs using liposomes of reduced size. Int J Pharm 315(2): 140-147.

10. Damborg P, Broens EM, Chomel BB, Guenther S, Pasmans F, et al. (2015) Bacterial Zoonoses Transmitted by Household Pets: State-of-the-Art and Future Perspectives for Targeted Research and Policy Actions. J Comp Pathol 155(1): 27-40.

11. Wells K, Gibson DI, Clark NJ, Ribas A, Morand S, et al. (2018) Global spread of helminth parasites at the human-domestic animal-wildlife interface. Glob Change Biol 24(1): 3254-3265.

12. Marks SL, Rankin SC, Byrne BA, Weese JS (2011) Enteropathogenic bacteria in dogs and cats: diagnosis, epidemiology, treatment, and control. J Vet Intern Med 25(6): 1195-2008.

13. Gilbert MJ, Kik M, Timmerman AJ, Severs TT, Kusters JG, et al (2014) Occurrence, diversity, and host association association of intestinal Campylobacter, Arcobacter, and Helicobacter in reptiles. PLoS One 9(7): 1-8.

14. Müller S, Janssen T, Wieler LH (2014) Multidrug resistant Acinetobacter baumannii in veterinary medicine e emergence of an underestimated pathogen? Berl Munch Tierarztl Wochenschr 127(11-12): 435-446.

15. Woodford N, Wareham DW, Guerra B, Teale C (2014) Carbapenemaseproducing Enterobacteriaceae and non-Enterobacteriaceae from animals and the environment: an emerging public health risk of our own making? J Antimicrob Chemother 69(2): 287-291.

16. Munoz J, Mayer DC (2016) Toxoplasma gondii and Giardia duodenalis infections in domestic dogs in New York City public parks. Vet J 211(1): 97-99.

17. Alemayehu B, Alemayehu M (2017) Leishmaniasis: A Review on Parasite, Vector and Reservoir Host. Health Sci J 11(4): 1-6.

18. Jambulingam P, Pradeep Kumar N, Nandakumar S, Paily KP, Srinivasan R, et al. (2017) Domestic dogs as reservoir hosts for Leishmania donovani in thesouthernmost Western Ghats in India. Acta Trop 171(1): 64-67.

19. Esch KJ, Petersen CA (2013) Transmission and epidemiology of zoonotic protozoal diseases of companion animals. Clin Microbiol Rev 26(1): 58-85.

20. Schär F, Inpankaew T, Traub RJ, Khieu V, Dalsgaard A, et al. (2014) The prevalence and diversity of intestinal parasitic infections in humans and domestic animals in a rural Cambodian village. Parasitol Int 63(4): 597-603.

21. Boulaiz H, Alvarez PJ, Ramirez A, Marchal JA, Prados J, et al. (2011) Nanomedicine: Application Areas and Development Prospects. Int J Mol Sci 12: 3303-3321.

22. Meena NS, Sahni YP, Thakur D, Singh RP (2018) Applications of nanotechnology in veterinary. J Entomol Zool Stud 6(2): 167-175.

23. Chapman WL, Hanson WL, Alving CR, Hendricks LD (1984) Antileishmanial activity of liposome-encapsulated meglumine antimonate in the dog. Am J Vet Res 45(5): 1028-1032.

24. Alving CR (1986) Liposomes as drug carriers in leishmaniasis and malaria. Parasitol to 2: 101-107.

25. Mellors JW, Debs RJ, Ryan JL (1989) Incorporation of recombinant gamma interferon into liposomes enhances its ability to induce peritoneal macrophage antitoxoplasma activity. Infect Immun 57(1): 132-137.

26. El-Zawawy LA, El-Said D, Mossallam SF, Ramadan HS, Younis, SS (2015) Triclosan and triclosan-loaded liposomal nanoparticles in the treatment of acute experimental toxoplasmosis. Exp Parasitol 149: 5464.

27. Ingolfsdottir K (2002) Usnic acid. Phytochemistry 61(7): 729-736.

28. Pramyothin P, Janthasoot W, Pongnimitprasert N, Phrukudom S, Ruangrungsi N (2004) Hepatotoxic effect of (+) usnic acid from Usnea siamensis Wainio in rats, isolated rat hepatocytes and isolated rat liver mitochondria. J Ethnopharmacol 90(2,3): 381-387.

29. Si K, Wei L, Yu X, Wu F, Li X, et al. (2016) Effects of (+)-usnic acid and (+)-usnic acid-liposome on Toxoplasma gondii. Exp Parasitol 166: 6874.

30. Vinay PT, Ravindra BG, Vijaykumar M, Sunilchandra U, Kulkarni S (2017) Effect of enrofloxacin on hematological and biochemical parameters in dogs. T Pharm Innov, 6(2): 167-168.

31. Xie S, Yang F, Tao Y, Chen D, Qu W, et al. (2017) Enhanced intracellular delivery and antibacterial efficacy of enrofloxacin-loaded docosanoic acid solid lipid nanoparticles against intracellular Salmonella. Sci Rep 7: 41104 .

32. Baş AL, Şimșek A, Corlu M, Elmas M, Değim ZG (2002) Determination of intracellular concentrations of free and two types of liposomeencapsulated enrofloxacin in Anatolian shepherd dog monocytes. J Vet Med B 49: 289-293.

33. Bas AL, Simsek A, Erganis O, Corlu M (2005) Efficacies of liposomeencapsulated enrofloxacin against Staphylococcus aureus infection in Anatolian shepherd dog monocytes in vitro. Dtsch Tierarztl Wochenschr 112: 219-223.

34. Deĝim Z, Deĝim T, Bas L, Elmas M (2002) The use of liposomal enrofloxacin for intracellular infections in Kangal dogs and visualization of phagocytosis of liposomes. J Biomed Mater Res 61(2): 246-251.

35. Bas AL, Elmas M, Simsek A, Tras B, Yazar E, et al. (2000) Efficacies of free and liposome-encapsulated enrofloxacin (Baytrilß) against Staphylococcus aureus infection in Turkish shepherd dog neutrophils in vitro. Rev Med Vet 151(5): 415-420.

36. Ribeiro RR, Moura EP, Pimentel VM, Sampaio WM, Silva SM, et al. (2008) Reduced tissue parasitic load and infectivity to sand flies in dogs naturally infected by Leishmania (Leishmania) chagasi following treatment with a liposome formulation of meglumine antimoniate. Antimicrob Agents Chemother 52: 2564-2572.

37. da Silva SM, Amorim IF, Ribeiro RR, Azevedo EG, Demicheli C, et al. (2012) Efficacy of combined therapy with liposome-encapsulated meglumine antimoniate and allopurinol in treatment of canine visceral leishmaniasis. Antimicrob Agents Chemother 56: 2858-2867. 


\section{Your next submission with Juniper Publishers} will reach you the below assets

- Quality Editorial service

- Swift Peer Review

- Reprints availability

- E-prints Service

- Manuscript Podcast for convenient understanding

- Global attainment for your research

- Manuscript accessibility in different formats ( Pdf, E-pub, Full Text, Audio)

- Unceasing customer service

Track the below URL for one-step submission https://juniperpublishers.com/online-submission.php 